\title{
Structure and Properties of Multilayer Nanostructured Coatings TiN/MoN Depending on Deposition Conditions
}

\author{
A.D. Pogrebnjak ${ }^{a *}$, G. Abadias ${ }^{b}$, O.V. Bondar ${ }^{a}$, B.O. Postolnyi ${ }^{a}$, M.O. $\operatorname{Lisovenko}^{a}$, \\ O.V. Kyrychenko ${ }^{a}$, A.A. Andreev ${ }^{c}$, V.M. BeresneV ${ }^{d}$, D.A. Kolesnikov ${ }^{e}$ \\ AND M. OPIELAK ${ }^{f}$ \\ ${ }^{a}$ Sumy State University, Rymskogo-Korsakova 2, Sumy, 40007, Ukraine \\ ${ }^{b}$ Institute P', Université de Poitiers-CNRS-ENSMA, SP2MI, \\ TéléportÂ 2, F86962 Chasseneuil-Futuroscope CEDEX, France, France \\ ${ }^{c}$ National Science Center, Kharkov Institute of Physics and Technology, \\ Akademicheskaya 1, Kharkiv, 61108, Ukraine \\ ${ }^{d}$ Kharkiv National University, maj. Nezalezhnosti 4, Kharkiv, 61022, Ukraine \\ ${ }^{e}$ Belgorod State University, Pobedy 85, Belgorod, 308015, Russia \\ ${ }^{f}$ Institute of Transport, Combustion Engines and Ecology, Lublin University of Technology, \\ Nadbystrzycka 36, 20-618 Lublin, Poland
}

\begin{abstract}
This work presents the results of TiN/MoN coatings studying. These multilayer nanostructured coatings demonstrate dependence on depositions conditions on nanometer level. The influence of nanosized monolayer thickness on structure changing and properties of nanocomposite multilayer coatings TiN/MoN was found. Multilayer TiN/MoN coatings of the total thickness from 6.8 to $8.2 \mu$ m were obtained using C-PVD method. Thicknesses of monolayers were 2, 10, 20, $40 \mathrm{~nm}$. The structure of samples was studied using X-ray diffraction (Bruker D-8 Advance) in $\mathrm{Cu} K_{\alpha}$ radiation, high resolution transmission electron microscopy with diffraction CFEI EO Techai F200, scanning electron microscopy with energy dispersive X-ray spectroscopy (JEOL-7001F), and microhardness measurements in dependence on indenter load. Scratch tests (friction, wear, etc.) were also provided using Rockwell-C diamond indenter (CSM Revetest Instruments) with a tip radius of $200 \mu \mathrm{m}$. Friction and wear behavior were evaluated using ball-on-plate sliding test on a UMT-3MT tribometer (CETR, USA). With decreasing monolayer thickness the hardness value increases, and the size of nanograins reduces. The values obtained for the friction coefficient of the multilayer system is much smaller than in nanostructured coatings of TiN (nc) or $\mathrm{MoN}(\mathrm{nc})$. Annealing showed formation of a $(\mathrm{Ti}, \mathrm{Mo}) \mathrm{N}$ solid solution and small growth of nanocrystals.
\end{abstract}

DOI: $10.12693 /$ APhysPolA.125.1280

PACS: 61.46.-w, 62.20.Qp, 62.25.-g

\section{Introduction}

Nanocomposite materials demonstrate unique properties because of small grains size (less than $10 \mathrm{~nm}$ ) and greater importance of the boundary zones [1]. Recently, multilayered, multicomponent and nanostructured coatings are the basis of protection products with various functionality, such as increase of hardness, wear, corrosion resistance to high-temperature oxidation, fatigue etc. [1-3]. TiN [3-5] and Mo [2, 4, 6] coatings provide wear protection (when applying them to churlish cutting tools) and in some cases they protect from corrosion.

It is known that hardness of Mo coatings is $32 \div 55 \mathrm{GPa}$ and their deposition on cutting tools increases wear resistance several times. At the same time, TiN coatings have hardness $32 \mathrm{GPa}$ and in individual cases hardness rises to $40 \mathrm{GPa}$ or higher [2]. It is also known that Ti-Mo-N multilayer coatings show 2-4 times durability increase in comparison with conventional coatings

*corresponding author; e-mail: alexp@i.ua based on TiN. However, the heat resistance of these coatings is not so high. Coatings begin to oxidize and their hardness sharply decreases when temperature reached $550 \div 600{ }^{\circ} \mathrm{C}[7-10]$.

Therefore, the development of new nanocomposite (nanostructured) multilayer coatings based on $\mathrm{TiN} / \mathrm{MoN}$ with high physical-mechanical and tribological properties and their studying are actual problems of modern materials science and solid state physics. The solving of these tasks will allow to increase protective properties range of these coatings.

In this paper, we investigate structure and properties of multilayer nanostructured coatings $\mathrm{TiN} / \mathrm{MoN}$ depending on monolayer thickness and deposition conditions.

\section{Experimental details}

Multilayer biphasic nanostructured TiN-MoN coatings were deposited using vacuum-arc device "BULAT-6", which allows deposition of nanostructured coatings in pulsed mode with variable pulse amplitude and pulse frequency.

Figure 1 shows a scheme of obtaining the required coatings. The vacuum chamber (1) is equipped with a system 
of automatic nitrogen pressure control (2) and two evaporators. One of them (3) has molybdenum mk. MCHVP as the evaporated material and the other one (5) has titanium mk. BT1-0. Substrate holder (5) is mounted on rotating chamber device as a stainless steel plate which size is of $300 \times 300 \mathrm{~mm}^{2}$, in the center of steel plate substrates (6) are placed. Substrates are made of stainless steel X18H9T disks of $19 \mathrm{~mm}$ diameter and $3 \mathrm{~mm}$ thickness. BULAT-6 is also equipped with dc voltage source $(7)$, the value of which varies between $5 \div 1000 \mathrm{~V}$, and high-voltage impulse generator (8) with adjustable voltage pulse amplitude of $0.5 \div 2 \mathrm{kV}$ and repetition frequency $0.5 \div 0.7 \mathrm{kHz}$. Thickness of deposited nanosized monolayers (TiN and MoN) was about 2, 10, 20, $40 \mathrm{~nm}$ and total thickness was in the range from 6.8 to $8.2 \mu \mathrm{m}$. Process of biphasic multilayer coatings deposition was carried out at pressure of $1.33 \times 10^{-3} \mathrm{~Pa}$ and $1 \mathrm{kV}$ substrate potential. Then substrates cleaning process was carried out with molybdenum ions during $3 \div 5 \mathrm{~min}$ on each of both sides. Further, nitrogen was injected into the chamber and nitrides of titanium and molybdenum were deposited on opposite substrate sides. When first layers have been finished, deposition stops and substrates turn over on the angle of $180^{\circ}$. Then deposition starts again. In this way average deposition speed was $1 \div 2 \mathrm{~nm} / \mathrm{s}$. The arc current during deposition was $85 \div 90 \mathrm{~A}$, nitrogen pressure in chamber was $0.665 \mathrm{~Pa}$, the distance between evaporator and substrate was $250 \mathrm{~mm}$ and substrate temperature was $250 \div 350^{\circ} \mathrm{C}$. During deposition of coatings negative potential impulses (with duration of $10 \mu \mathrm{s}$, repetition frequency $7 \mathrm{kHz}$ and constant negative potential $5 \div 400 \mathrm{~V}$ ) were applied to the substrate.

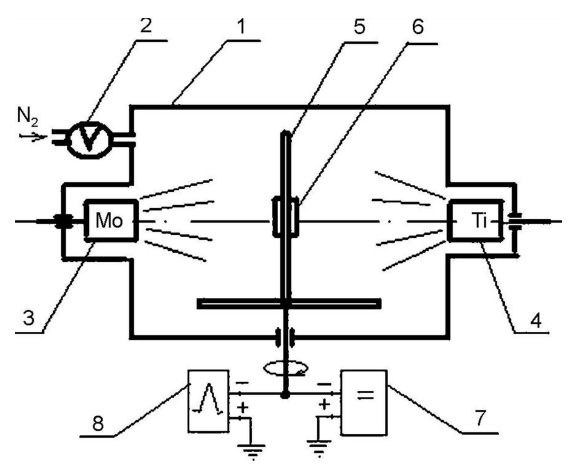

Fig. 1. "BULAT-6" device scheme for multilayer coatings deposition. 1 - vacuum chamber, 2 - automatic control system of the nitrogen pressure, 3 - molybdenum evaporator, 4 - titanium evaporator, 5 - substrate holder, $6-$ substrate, $7-\mathrm{DC}$ voltage source, 8 - high-voltage impulse generator.

The Rutherford backscattering (RBS) on $\mathrm{He}^{+}$ions with energy $1.7 \mathrm{MeV}$ was used to complete information about elemental structure (scattering angle $\theta=170^{\circ}$ at normal probing ions falling, detector energy resolution was $16 \mathrm{keV}$, helium ions dose was $5 \mu \mathrm{m})$. Microbundle of protons ( $\mu$-PIXE) was applied with initial energy
1.4 MeV based on electrostatic accelerator IAP (Sumy, Ukraine) with beam size $0.5 \mu \mathrm{m}$ charge $3 \times 10^{-10} \mathrm{~s} /$ pixel, raster $50 \times 50$, scanning step $0.5 \mu \mathrm{m}$.

Investigation of coatings microstructure and element composition was carried out using several scanning electron-ion microscopes (Quanta 200 3D, Quanta 600 FE-SEM) equipped with X-ray detector system PEGASUS 2000. We also used a scanning electron microscope JEOL-7001F with microanalysis EDX (Japan). Coatings structure and phase composition were analyzed using XRD (Bruker Advanced 8) in $\mathrm{Cu} K_{\alpha}$ radiation. Hardness and elastic modulus measurement were carried out with CSM company device (Switzerland). Tribological researches were performed using the scratch test REVETEST (CSM Instruments), where friction factor $\mu$, wear resistance and acoustic emission by pyramid Rockwell-C indentation were measured. Transverse sections were prepared for the analysis of multilayer coatings and thickness determination. The texture perfection degree $(\Delta \psi)$ was determined over the width at half maximum of the diffraction lines taken at $\theta$-scanning. Diffraction profiles isolation in case of overlapping carried out using computer program overlapping lines separation "New profile" developed by NTU "KhPI". Volume fraction of phases in the coatings was calculated by standard methods taking into account the intensity and the integrated reflectance of several lines of each phase. Phase composition analysis was performed using ASTM cata$\operatorname{logs}$.

\section{Results and discussion}

There is only one phase with fcc lattice (structural type $\mathrm{NaCl}$ ) formed in coating at a low substrate potential $40 \mathrm{~V}$ at monolayer thickness nearby $2 \mathrm{~nm}$. When substrate potential increased to $-230 \mathrm{~V}$, it caused formation of two-phase TiN system and high-temperature $\gamma-\mathrm{Mo}_{2} \mathrm{~N}$ with phase ratio $\mathrm{TiN} / \mathrm{MoN}$ equal to $90 / 10$, respectively. The appearance of a two-phase condition is an intensive ion bombardment which promotes nanograins grinding and interfaces formation. This is accompanied by separate $\mathrm{Mo}_{2} \mathrm{~N}$ layers with cubic lattice and interface formation. In turn, it leads to stress growing in the TiN phase and period increase in tense cross-section. In this case layers structure is columnar.

Formation of the two-phase structural state with an average $\mathrm{TiN}$ and $\gamma-\mathrm{Mo}_{2} \mathrm{~N}$ cubic phase grade 60 vol.\% and 40 vol. $\%$ occurs when monolayers thickness increases to $10 \mathrm{~nm}$. These values are close to Ti and Mo concentrations (62.3 at.\% and 36.8 at.\%, respectively, see Fig. 2b), which were obtained by EDX.

The full cross-section of nanostructured coatings is presented in the next figure (Fig. 3a). Figure 3b shows striped TiN nanosized layers — dark areas and MoN light areas which are well recognizable at this zoom.

The appearance of interface specific volume caused by high $\gamma-\mathrm{Mo}_{2} \mathrm{~N}$ phase level accompanied by high $\gamma-\mathrm{Mo}_{2} \mathrm{~N}$ phase level is accompanied by high compressive stress 

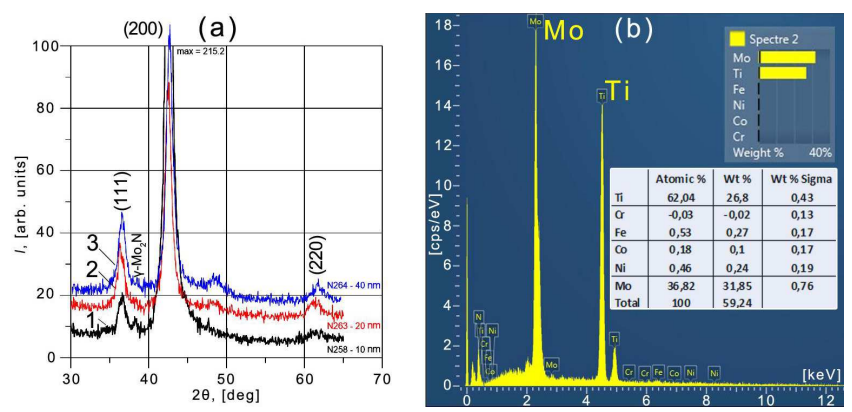

Fig. 2. Properties of nanostructured samples: (a) fragments of the diffraction patterns (XRD), obtained for coating samples with monolayer thickness $10,20,40 \mathrm{~nm}$, (b) the energy-dispersive spectrum, obtained on multilayer nanocomposite coating with monolayer thickness $40 \mathrm{~nm}$.

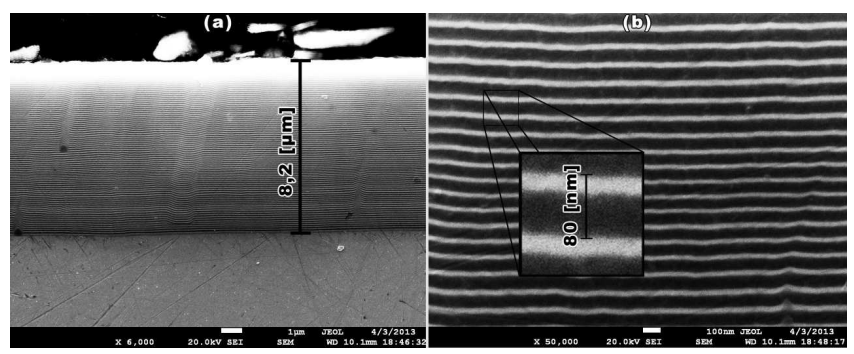

Fig. 3. The microphotographs of cross-sections of nanostructured multilayer $\mathrm{Ti}-\mathrm{Mo}-\mathrm{N}$ coatings: (a) the general view. The coating thickness is $8.2 \mu \mathrm{m}$, (b) the cross-section fragment, $50000 \times$ zoom. The monolayer thickness is $20 \mathrm{~nm}$.

growth in titanium nitride, it achieved maximum hardness 32 GPa (see Fig. 4a).
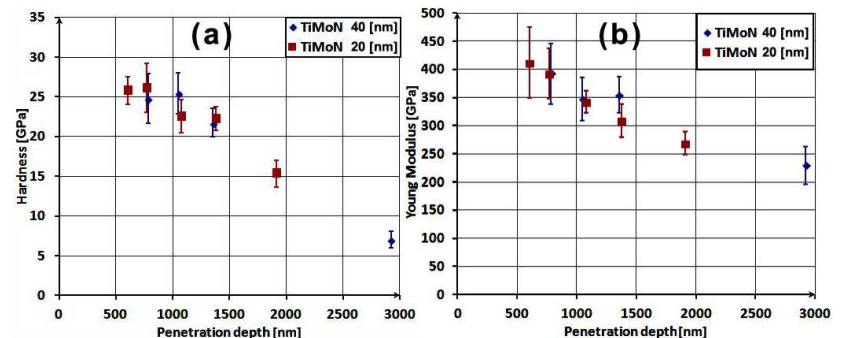

Fig. 4. The microhardness characteristics: (a) the dependence of microhardness $H$ on the indenter penetration depth for monolayers thickness 20 and $40 \mathrm{~nm}$,

(b) the dependence of elastic modulus $E$ on the indenter penetration depth for monolayers thickness 20 and $40 \mathrm{~nm}$.

We wonder that only $\gamma-\mathrm{Mo}_{2} \mathrm{~N}$ phase presents in molybdenum nitride and no $\beta-\mathrm{Mo}_{2} \mathrm{~N}$ phase is formed, although both of them can be formed in case of vacuum-arc deposition. This can be explained by two-stage phase composition of multilayered nanostructured coating. At the initial growth of $\mathrm{Mo}_{2} \mathrm{~N}$ the determining factor is TiN lat- tice atomic sequence. Therefore, there is a $\gamma-\mathrm{Mo}_{2} \mathrm{~N}$ cubic modification stabilization with molybdenum nitride layer growing. This is accompanied by a macrodeformation resetting and interface formation caused by structured macrostress of relatively high thickness. Volume content of the phases accurately corresponds to the expected in according to the EDX analysis (70 $\hat{\mathrm{A}}$ at.\% TiN and $30 \hat{\mathrm{A}}$ at. $\left.\% \mathrm{Mo}_{2} \mathrm{~N}\right)$ for samples with coating thickness nearby $20 \hat{\mathrm{A}} \mathrm{nm}$.

\section{Conclusions}

The tribological properties analysis shows that surface roughness $R$ a reaches the value $0.3 \mu \mathrm{m}$, friction coefficient varies from 0.09 to 0.12 . Critical load (when coating starts to break) ranges from $425 \mathrm{~N}$ at monolayer thickness $40 \mathrm{~nm}$, and reaches $(610 \div 648) \mathrm{N}$ at thickness 10 and $2 \mathrm{~nm}$. Thus, the smaller monolayer thickness, the higher load. This shows that one nitride monolayer envelops nanograins in the last case [11-13]. Therefore, nanocomposite strength increases by grains shift prevention (slipping). According to Koehler's model [14] the possible mechanism of hardness increasing is transfer of valence charge [15], reduction of nanograins size and mixing entropy.

The smallest wear was observed under deposition conditions for monolayers thickness 2 and $10 \mathrm{~nm}$, equals 0.148 for counterbody and $2.327 \times$ $10^{-5}\left[\mathrm{~mm}^{3} \mathrm{~N}^{-1} \mathrm{~mm}^{-1}\right]$ for coating. Samples annealing during $2 \mathrm{~h}$ at temperature $800^{\circ} \mathrm{C}$ in an oven under vacuum $10^{-2} \mathrm{~Pa}$ causes reducing of compressive stress and small nanograins growth to $10 \div 15 \%$ (no more).

\section{Acknowledgments}

The work was performed within the framework of scientific-technical cooperation program with the University of Poitiers, as well as comprehensive state program "Development of the basis for formation of multicomponent nanostructured superhard coatings with high physical and mechanical properties" (no. 0112U001382) and "Physical principles of plasma technologies for complex processing of multicomponent materials and coatings" (no. 0113U000137c).

\section{References}

[1] A.D. Pogrebnjak, A.P. Shpak, N.A. Azarenkov, V.M. Beresnev, Phys. Usp. 52, 29 (2009).

[2] M.K. Kazmanli, M. Urgen, A.F. Cakir, Surf. Coat. Technol. 167, 77 (2003).

[3] A.D. Pogrebnjak, A.G. Ponomarev, A.P. Shpak, Yu.A. Kunitskii, Phys. Usp. 55, 270 (2012).

[4] A.D. Pogrebnyak, V.M. Beresnev, A.Sh. Kaverina, A.P. Shypylenko, O.V. Kolisnichenko, K. Oyoshi, Y. Takeda, H. Murakami, D.A. Kolesnikov, M.S. Prozorova, Tech. Phys. Lett. 39, 189 (2013). 
[5] A.D. Pogrebnjak, A.P. Shpak, V.M. Beresnev, D.A. Kolesnikov, Yu.A. Kunitskii, O.V. Sobol, V.V. Uglov, F.F. Komarov, A.P. Shypylenko, N.A. Makhmudov, A.A. Demyanenko, V.S. Baidak, V.V. Grudnitskii, J. Nanosci. Nanotechnol. 12, 9213 (2012).

[6] R. Krause-Rehberg, A.D. Pogrebnyak, V.N. Borisyuk, M.V. Kaverin, A.G. Ponomarev, M.A. Bilokur, K. Oyoshi, Y. Takeda, V.M. Beresnev, O.V. Sobol, Phys. Met. Metallogr. 114, 672 (2013).

[7] A.D. Pogrebnjak, V.M. Beresnev, A.A. Demianenko, V.S. Baidak, F.F. Komarov, M.V. Kaverin, N.A. Makhmudov, D.A. Kolesnikov, Phys. Solid State 54, 1882 (2012).

[8] T.N. Koltunowicz, P. Zhukowski, A.K. Fedotov, A.V. Larkin, A. Patryn, B. Andryevskyy, A. Saad, J.A. Fedotova, V.V. Fedotova, Elektronika ir Elektrotechnika (Electron. Electr. Eng.) 19, 37 (2013).

[9] P. Zukowski, T. Koltunowicz, J. Partyka, Yu.A. Fedotov, A.V. Larkin, Vacuum 83, S275 (2009).

[10] I.A. Lyashenko, A.V. Khomenko, L.S. Metlov, Techn. Phys. 55, 1193 (2010).
[11] A.D. Pogrebnjak, J. Nanomater. 2013, ID 780125, (2013).

[12] A.D. Pogrebnjak, O.V. Sobol, V.M. Beresnev, P.V. Turbin, G.V. Kirik, N.A. Makhmudov, M.V. Il'yashenko, A.P. Shypylenko, M.V. Kaverin, M.Yu. Tashmetov, A.V. Pshyk, Nanostruct. Mater. Nanotechnol. IV: Ceram. Eng. Sci. Proc. 31, 127 (2010).

[13] A.V. Khomenko, N.V. Prodanov, Condens. Matter Phys. 11, 615 (2008).

[14] V. Ivashchenko, S. Veprek, A.D. Pogrebnjak, in: Proc. Int. Conf. Nanomaterials: Applications and Properties, Vol. 1, Ed.: A.D. Pogrebnjak, Sumy State University, Sumy 2012, p. 03PCSI19.

[15] A.D. Pogrebnjak, S.N. Bratushka, V.M. Beresnev, N. Levintant-Zayonts, Russ. Chem. Rev. 82, 1135 (2013). 